Pesq. Vet. Bras. 29(4):312-316, abril 2009

\title{
Aspectos histológicos e morfométricos dos testículos de gatos domésticos (Felis catus) ${ }^{1}$
}

\author{
Carlos A.O. Silva ${ }^{2}$, Silvia H.V. Perri ${ }^{3}$, Marion B. Koivisto ${ }^{4}$, Adelina M. Silva ${ }^{4}$, \\ Roberto G. Carvalho ${ }^{3}$ e Cristina M.R. Monteiro ${ }^{3^{*}}$
}

\begin{abstract}
Silva C.A.O., Perri S.H.V., Koivisto M.B., Silva A.M., Carvalho R.G. \& Monteiro C.M.R. 2009. [Histological and morphometric evaluation of the testes of cats (Felis catus).] Aspectos histológicos e morfométricos dos testículos de gatos domésticos (Felis catus). Pesquisa Veterinária Brasileira 29(4):312-316. Curso de Medicina Veterinária, Faculdade de Odontologia, Universidade Estadual Paulista, Rua Clóvis Pestana 793, Araçatuba, SP 16050-680, Brazil. E-mail: monteiro@fmva.unesp.br

This paper deals with a comparative histologic and morphometric study of the testes of domestic cats distributed into two groups: Group 1, cats until 1 year of age, and Group 2, cats over 1 year. It was found that: (1) at 4 months of age the seminiferous tubules were poorly developed, appeared as seminiferous cords without lumen, lined by a low epithelium, and showed undifferentiated Sertoli cells and scarce interstitial tissue; (2) at 5 months the seminiferous tubules began to differentiate with increase in tubular diameter and lumen, the other tubular structures remaining similar to those previous referred; (3) at 6 and 7 months of age spermatocytogenesis began to appear, Leydig cells were large, polyhedral in shape, with vacuolated cytoplasm and clear nuclei, resting on a sparse interstitial tissue with few blood vessels; (4) 1-year-old cats showed testicular histological features of an adult animal, had seminiferous tubules of large diameter and high seminiferous epithelium with small lumen, and Leydig cells of different sizes, with polyhedral shape, vacuolated cytoplasm, clear nuclei and evident nucleoli resting in a sparse interstitial tissue with some blood vessels; (5) in Group 1 the average diameter of the seminiferous tubules was $160.58 \mu \mathrm{m}$, and $185.94 \mu \mathrm{m}$ in Group 2; $(6)$ the height of the seminiferous epithelium was $49.51 \mu \mathrm{m}$ for Group 1 and $63.29 \mu \mathrm{m}$ for Group 2; (7) the largest measures of the analyzed parameters were found in animals of Group 2, with functional reproductive organs.
\end{abstract}

INDEX TERMS: Histology, morphometry, testes, cats.

RESUMO.- Nesta pesquisa foram obtidos dados histológicos e morfométricos comparativos sobre os testículos de gatos, pós-orquiectomia, divididos em dois grupos: Grupo 1, gatos com até 1 ano de idade e Grupo 2, ani-

\footnotetext{
${ }^{1}$ Recebido em 17 de junho de 2008.

Aceito para publicação em 9 de janeiro de 2009.

2 Graduando, Bolsista FAPESP, do Curso de Medicina Veterinária, Faculdade de Odontologia, Universidade Estadual Paulista (Unesp), Campus de Araçatuba, Rua Clóvis Pestana 793, Araçatuba, SP 16050680, Brasil.

${ }^{3}$ Departamento de Apoio, Produção e Saúde Animal, Curso de Medicina Veterinária, Faculdade de Odontologia, Unesp-Araçatuba, SP.

${ }^{4}$ Departamento de Clínica, Cirurgia e Reprodução Animal, Curso de Medicina Veterinária, Faculdade de Odontologia, Unesp-Araçatuba, SP. *Autor para correspondência: monteiro@fmva.unesp.br
}

mais acima de 1 ano. Verificou-se que: (1) aos 4 meses de idade os túbulos seminíferos apresentaram-se pouco desenvolvidos e com ausência de luz, epitélio seminífero baixo, células de Sertoli indiferenciadas e tecido intersticial escasso; (2) aos 5 meses os túbulos seminíferos começaram a se diferenciar com aumento do diâmetro e luz tubulares e as demais estruturas permaneceram semeIhantes à observação anterior; (3) aos 6-7 meses ocorreu o início da espermatogênese e espermiogênese; as células de Leydig apareceram maiores, poliédricas com citoplasma vacuolizado e núcleo claro, e tecido intersticial esparso com poucos vasos sangüíneos; (4) os animais com 1 ano de idade apresentaram morfologia testicular igual à do animal adulto, com túbulos seminíferos de maior diâmetro, epitélio germinativo alto e luz tubular peque- 
na, as células de Leydig aparecendo poliédricas, com dimensões variadas, citoplasma vacuolizado, núcleo claro e nucléolo evidente, e espaço intertubular seminífero variado com vasos sanguíneos, predominantemente evidentes; (5) no Grupo 1 o diâmetro médio dos túbulos seminíferos foi de $160,58 \mu \mathrm{m}$ e no Grupo 2 foi de $185,94 \mu \mathrm{m}$, sendo os valores médios significantes entre si; (6) a altura média do epitélio seminífero foi de 49,51 $\mu$ m para o Grupo 1 e de $63,29 \mu \mathrm{m}$ para o Grupo 2, estaticamente significantes; (7) os maiores valores mensurados foram obtidos para os gatos do Grupo 2, por serem gatos adultos e portanto com os órgãos reprodutores funcionais.

TERMOS DE INDEXAÇÃO: Histologia, morfometria, testículos, gatos.

\section{INTRODUÇÃO}

O gato é um animal, geralmente, belo, maleável e harmonioso em sua anatomia externa, e é hoje um dos animais domésticos, de adorno, bastante difundidos e cuja popularidade está alcançando aquela do cão, que já é considerada grande (Pugnetti 1991). Apesar de haver uma população expressiva de gatos mantidos pelo homem, como mamíferos de estimação, as pesquisas sobre a reprodução da espécie são pouco freqüentes e como modelo de laboratório o seu uso está aquém de outros animais domésticos (Concanon 1989). O conhecimento da função reprodutiva masculina no gato doméstico é importante e pode vir a ser um modelo valioso para a fisiologia da reprodução felina, sobretudo para as espécies ameaçadas de extinção (Wildt et al. 1986, Goodrowe et al. 1989, Pukazhenthi et al. 2001).

Relativamente, há poucos relatos na literatura sobre a estrutura do testículo, do processo espermatogênico e da morfometria testicular em gatos (Elcock \& Schonning 1984, Nie et al. 2002, França \& Godinho 2003). Portanto, os estudos histológicos são importantes para se verificar quaisquer variações que possam ocorrer nos testículos de gatos domésticos em estado reprodutivo, que possa prejudicar, por exemplo, o processo espermatocitogenético e eventuais "protocolos" de coleta de sêmen felino, o que motivou, também, a realização deste trabalho.

\section{MATERIAL E MÉTODOS}

Para este estudo foram utilizados 20 testículos de gatos de diferentes idades, provenientes de animais orquiectomizados no Hospital Veterinário do Curso de Medicina Veterinária, Unesp, Campus de Araçatuba, SP, os quais foram separados em dois grupos: grupo 1 proveniente de 10 gatos jovens (com até 1 ano de idade) e grupo 2 proveniente de 10 gatos adultos (acima de 1 a 8 anos de idade). Com o objetivo de realizar as análises histológicas e morfométricas, foram coletados os testículos inteiros, que foram recortados em fragmentos adequados e fixados em solução de Bouin durante 24 horas. Posteriormente, foi selecionado apenas um fragmento testicular de cada espécime, obtido em corte longitudinal, tendo aproximadamente $3 \mathrm{~mm}$ de espessura, visando o processamento histológico usual com inclusão em paraplast ${ }^{\mathrm{TM}}$ e microtomia.
Os cortes histológicos com $5 \mathrm{~mm}$ de espessura foram, a seguir, submetidos às colorações histológicas com $\mathrm{HE}$, tricrômico de Mallory para verificar a presença de fibras colágenas e Verhoeff para detectar fibras elásticas. Foram analisados, ao microscópio óptico, o padrão histológico da túnica albugínea, do tecido conjuntivo intersticial, do epitélio seminífero, e a presença e morfologia das células intersticiais. A análise morfométrica foi realizada por mensurações dos diâmetros dos túbulos seminíferos e de altura do epitélio germinativo, utilizando-se 30 cortes transversais de túbulos seminíferos, por amostra. Para esse fim foi utilizado o programa computacional "Image J" (USA), que é um programa para análises de imagens. A análise estatística foi feita utilizando-se o teste "t" de Student para comparar dois grupos independentes.

\section{RESULTADOS}

\section{Histologia}

Grupo 1. Nos gatos com até 1 ano de idade, a túnica albugínea em todos os testículos examinados apareceu espessa, formada por tecido conjuntivo denso moderadamente modelado. Ocorreram grande quantidade de fibras colágenas e poucas e discretas fibras elásticas, com emissão de septos delgados para o interior do parênquima testicular, os quais também eram constituídos, predominantemente, por fibras colágenas. Aos quatro meses de idade, os túbulos seminíferos apresentaram valores médios de diâmetro tubular, pequenos, ausência de luz tubular (Fig.1), epitélio germinativo pouco desenvolvido e células de Sertoli indiferenciadas. As células de Leydig eram arredondadas com citoplasma vacuolizado, núcleo claro e nucléolo evidente em meio ao tecido intersticial escasso. Aos 5 meses, os túbulos seminíferos apresentaram aumento evidente de diâmetro, presença de luz tubular (Fig.2), porém o epitélio seminífero era pouco desenvolvido e as células de Sertoli estavam indiferenciadas. As células germinativas e o tecido intersticial eram semelhantes às observações anteriores. Aos 6 e 7 meses, os septos testiculares eram mais evidentes (Fig.3), e houve o início da espermatocitogênese. As células de Leydig eram grandes e poliédricas com citoplasma vacuolizado e núcleo claro. O tecido intersticial apareceu esparso e com poucos vasos sangüíneos. Os gatos com 1 ano de idade apresentaram morfologia testicular geral similar à dos animais adultos.

Grupo 2. Os gatos com idades acima de 8 anos de idade apresentaram a túnica albugínea testicular espessa, formada por fibras colágenas e por algumas discretas fibras elásticas (Fig.4), túbulos seminíferos com diâmetro grande, epitélio germinativo alto e com fases diferentes de desenvolvimento e diferenciação dos espermatozóides (Fig.5). As células de Leydig apareceram poliédricas com diferentes tamanhos. Os seus citoplasmas eram vacuolizados, núcleos claros e nucléolos evidentes, e o espaço intersticial era de dimensões variáveis com vasos sanguíneos evidentes. As células de Sertoli já estavam diferenciadas e desenvolvidas, dispostas de modo uniforme. Elas apresentavam formato piramidal e alongado, contornos irregulares, com suas bases largas sobre a 
membrana basal. O núcleo das células de Sertoli aparecia esférico, oval ou piriforme localizado na parte alargada e basal da célula (Fig.6).

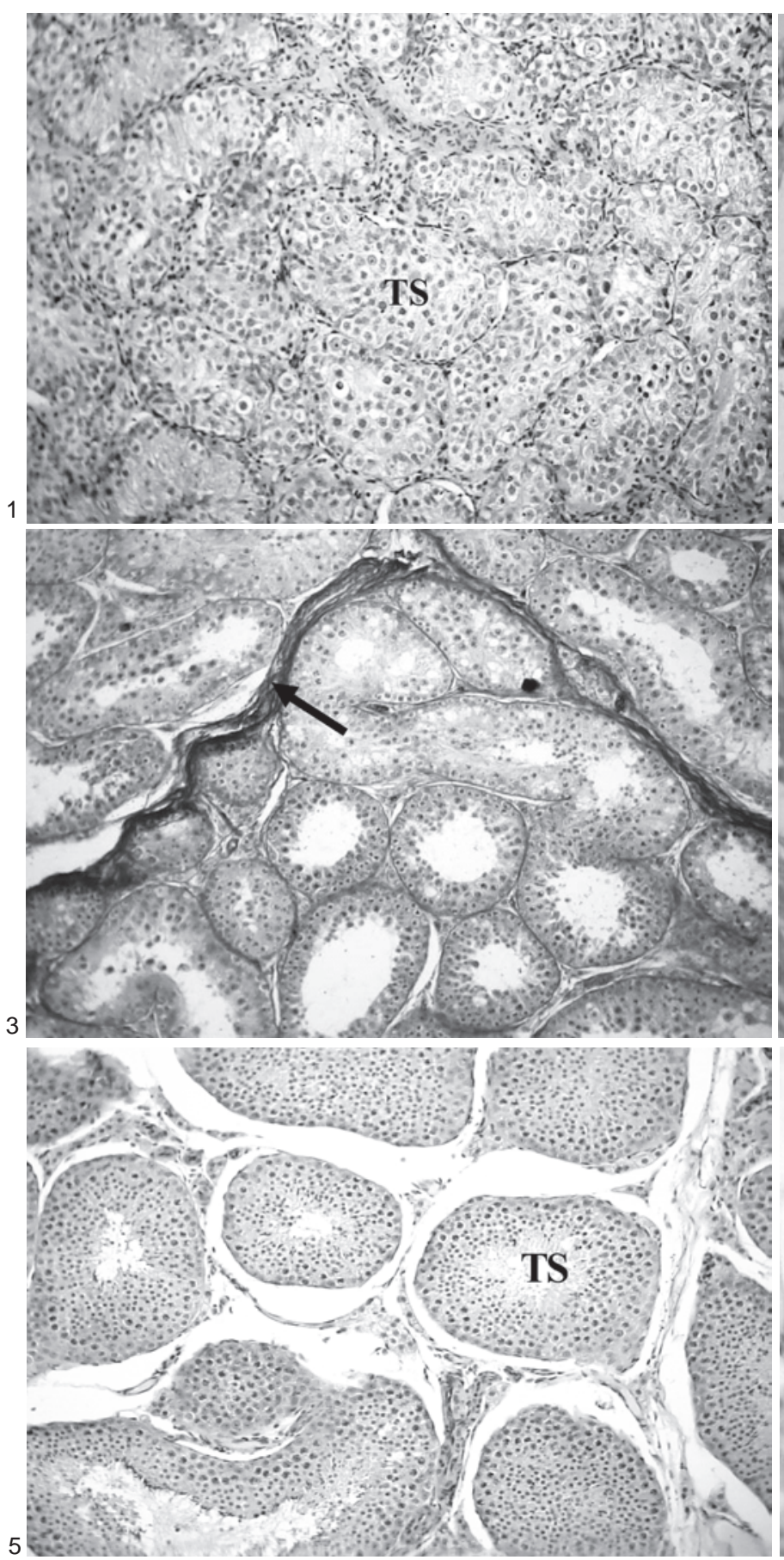

Fig.1. Túbulos seminíferos (TS) sem luz, em testículo de gato com 4 meses de idade. HE, obj.10x.

Fig.3. Septo (seta) em testículo de gato com 7 meses de idade. Tricrômico de Mallory, obj.10x.

Fig.5. Túbulos seminíferos (TS) em testículo de gato com 3 anos de idade. HE, obj.10x.

\section{Morfometria}

Os resultados da histomorfometria mostraram-se relevantes, com base no teste " $\mathrm{t}$ " de Student, para se com-

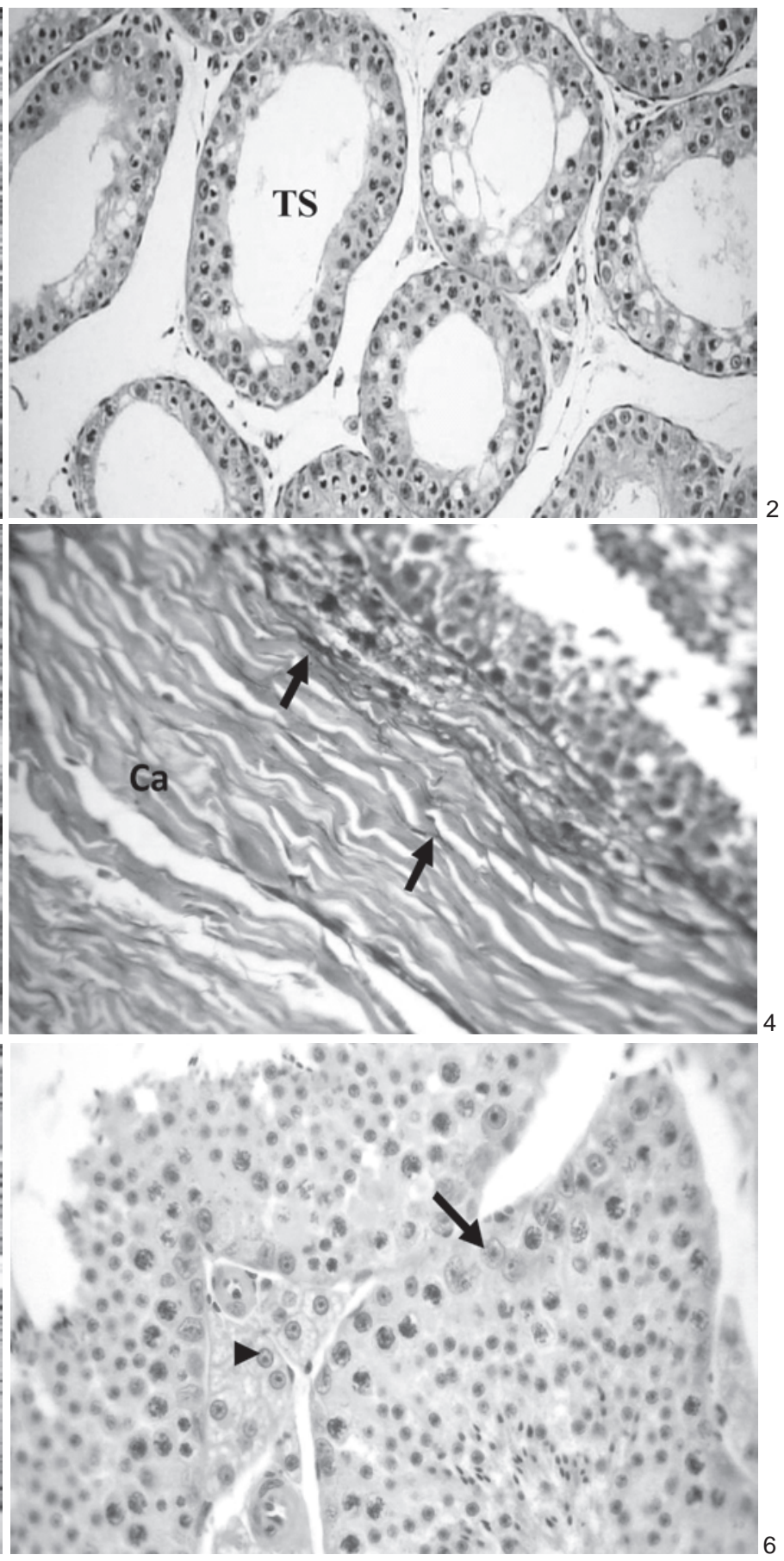

Fig.2. Túbulos seminíferos (TS) com luz em testículo de gato com 5 meses de idade. HE, obj.10x.

Fig.4. Cápsula albugínea (Ca) e fibras elásticas discretas (setas) em testículo de gato com 3 anos de idade. Verhoeff, obj.40x.

Fig.6. Núcleo de célula de Sertoli (seta) e células de Leydig (cabeça de seta) em testículo de gato com 8 anos de idade. HE, obj.40x. 


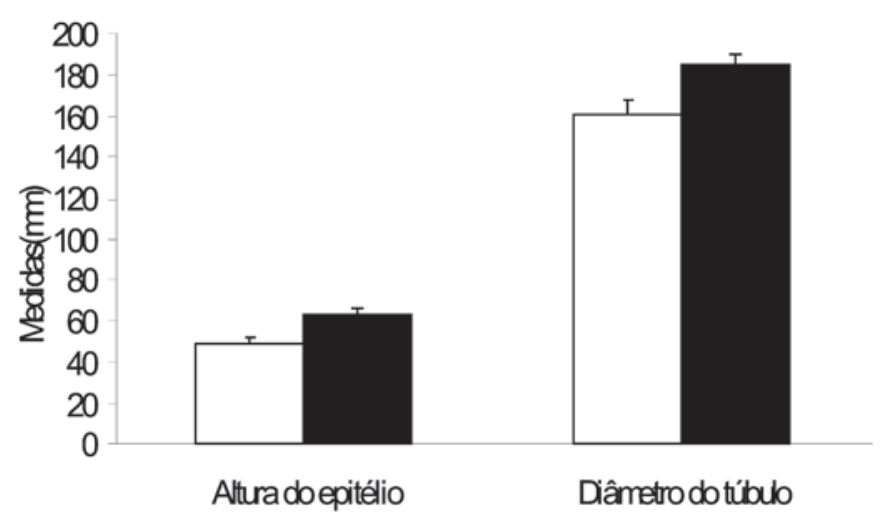

口Jovers घAdutos

Fig.7. Média e erro padrão da média da altura do epitélio e diâmetro do túbulo seminífero de testículos de gatos jovens e adultos. Araçatuba (SP), 2008.

Quadro 1. Média $(\bar{X})$ e erro padrão da média (EPM) para o diâmetro do túbulo seminífero e altura do epitélio de testículos de gatos jovens e adultos. Araçatuba-SP, 2008

\begin{tabular}{ccc}
\hline Grupo & \multicolumn{2}{c}{ Variável $(\overline{\mathrm{X}} \pm$ EPM $)$} \\
\cline { 2 - 3 } & Altura do epitélio $(\mathrm{mm})^{\mathrm{b}}$ & Diâmetro do túbulo $(\mathrm{mm})^{\mathrm{b}}$ \\
\hline Jovens & $49,51 \pm 2,59$ & $160,58 \pm 7,52$ \\
Adultos & $63,29 \pm 2,34$ & $185,94 \pm 5,03$ \\
$\mathrm{P}$ a & 0,0012 & 0,0117 \\
\hline
\end{tabular}

a Teste "t" de Student; b Valores numéricos médios.

parar os dois grupos independentes enfocados neste estudo (Quadro 1). No Grupo 1, com animais jovens, o valor do diâmetro médio dos túbulos seminíferos foi de $160,58 \mu \mathrm{m}$ e para o Grupo 2, com animais adultos, o valor do diâmetro tubular médio foi de $185,94 \mu \mathrm{m}$, considerados estatisticamente significantes. A altura média do epitélio seminífero foi de $49,51 \mu \mathrm{m}$ para o Grupo 1 e de $63,29 \mu \mathrm{m}$ para Grupo 2, também estaticamente significantes entre si (Quadro1, Fig.7).

\section{DISCUSSÃO}

A túnica albugínea testicular do gato, em todos os animais estudados, apareceu espessa, porém no Grupo 2 (animais adultos) apresentou-se mais espessa do que no grupo de animais jovens (Grupo 1), resultado este, em termos, diferente das observações de Elcoch \& Schoning (1990), que afirmaram que com o passar da idade, várias estruturas testiculares se alteram; dentre elas, o espessamento da túnica albugínea. A estruturação por tecido colágeno denso, moderadamente modelado e com poucas fibras elásticas da albugínea testicular, bem como a septação do parênquima que ocorre no gato, encontra semelhança na descrição de alguns autores (Banks, 1992; Dellmann, 1993 e Heyn et al. 1996).

Os testículos dos gatos com 4 meses de idade, apresentaram túbulos seminíferos com diâmetro pequeno (média de $121,32 \mathrm{~mm}$ ), relativamente ao dos animais adultos, com ausência de luz, epitélio germinativo pouco desenvol- vido e células de Sertoli indiferenciadas. Kawakami et al. (1991), de modo comparativo, relataram em testículos de cães com até 20 semanas de idade, que o diâmetro dos túbulos seminíferos era inferior a $100 \mu \mathrm{m}$, aumentando acentuadamente entre 22 e 28 semanas de idade, e que apenas células de Sertoli e espermatogônias foram observadas nos túbulos seminíferos até 16 semanas de idade.

Sanchez et al. (1993b), por outro lado, relataram no período neonatal de gatos, a presença de túbulos seminíferos separados por tecido intersticial bem desenvolvido; diâmetro tubular pequeno e ausência de lúmen com muitas células de Sertoli indiferenciadas, arredondadas com núcleos ovais e apenas uma ou duas espermatogônias, sendo estes resultados um pouco diferentes dos achados neste estudo.

As células de Leydig nos testículos de gatos com 4 a 5 meses de idade estavam presentes em número elevado confirmando os dados citados por Dellmann (1993) e Hoshino et al. (2002). Esses autores afirmaram que no gato as células intersticiais são mais abundantes do que nas outras espécies, e que praticamente preenchem os espaços intertubulares. A morfologia destas células foi similar à descrita pelos autores citados, no próprio gato.

Sanches et al. (1993a) encontraram três diferentes populações de células de Leydig o que talvez pudesse justificar os nossos achados quanto a, por exemplo, no período pós-natal (desde o nascimento até 1 mês de idade) as células de Leydig apareceram redondas ou poliédricas e com núcleo ovóide e excêntrico; de 2 a 5 meses elas eram semelhantes às observadas no período pós-natal, porém os núcleos continham grânulos de cromatina condensada e acúmulo de gotículas lipídicas no citoplasma.

Nos gatos com 5 meses de idade, os túbulos seminíferos apresentaram aumento do diâmetro, com média de $160,28 \mu \mathrm{m}$, presença de luz tubular com epitélio ainda pouco desenvolvido (altura de $43,30 \mu \mathrm{m}$ ), relativo ao dos animais adultos, e células de Sertoli indiferenciadas. Sanches et al. (1993b) relataram, também em gatos, que no período de 2 a 5 meses os diâmetros tubulares seminíferos aumentaram, e que a morfologia testicular geral foi semelhante à do período neonatal, correspondente a menos de 2 meses de idade, segundo os AA.

No período de 5-7 meses, entretanto, os diâmetros tubulares aumentaram, apresentaram luz e o epitélio seminífero assumiu as suas características de estratificação. Hoshino et al. (2002), já haviam confirmado esses dados, ao afirmar que durante a puberdade ocorre o crescimento ativo do epitélio germinativo dos túbulos seminíferos e o pleno desenvolvimento da luz tubular seminífera.

Aos 6-7 meses de idade, os septos tubulares eram mais evidentes e houve início da espermacitogênese e espermiogênese. A média dos diâmetros tubulares foi de $169,84 \mu \mathrm{m}$ para essas idades. De forma comparativa, Kawakami et al. (1991) encontraram em testículos de cães, com 28 semanas de idade, diâmetro tubular seminífero médio de $180 \mu \mathrm{m}$ e Sanches et al. (1993b) relataram que no período de 5 a 7 meses em gatos, os diâmetros tubu- 
lares aumentavam, apresentavam luz tubular, o epitélio seminífero começava a assumir características de estratificação e a espermatogênese estava plenamente estabelecida.

Nos gatos com 1 ano de idade a morfologia dos túbulos seminíferos já era similar à do animal adulto, mas verificaram-se diferenças significativas das médias aritméticas dos parâmetros analisados, comparando-se, por exemplo, os diâmetros dos túbulos seminíferos entre animais jovens e adultos com $160,58 \mu \mathrm{m}$ e com $185,94 \mu \mathrm{m}$, respectivamente, e também para a altura do epitélio que foi de $49,51 \mu \mathrm{m}$ para os animais jovens e de $63,28 \mu \mathrm{m}$ para os adultos (Quadro 1, Fig.7). Hoshino et al. (2002) acharam diferença significativa de $5 \%$ ao comparar os diâmetros máximo e mínimo dos túbulos seminíferos, sendo respectivamente, $210 \mu \mathrm{m}$ e $156 \mu \mathrm{m}$ para jovens e de $231 \mu \mathrm{m}$ e $170 \mu \mathrm{m}$ para adultos. Porém para a altura do epitélio seminífero, com o evoluir da idade, não houve diferença significante, sendo de $51 \mu \mathrm{m}$ para jovens e de $54 \mu \mathrm{m}$ para adultos, o que foi diferente de nossos achados.

Por outro lado, França \& Godinho (2000) encontraram diâmetro tubular seminífero médio de $220 \mu \mathrm{m}$ para gatos adultos. As mensurações para os diâmetros dos túbulos seminíferos dos autores, foram maiores do que as mensurações encontradas nessa pesquisa. Neubauer et al. (2004), no entanto, encontraram mensurações mais aproximadas aos nossos achados.

\section{CONCUSÕES}

Aos 4 meses de idade os túbulos seminíferos dos gatos apresentaram-se pouco desenvolvidos, ausência de luz, epitélio seminífero baixo, células de Sertoli indiferenciadas e tecido intersticial escasso;

Aos 5 meses os túbulos seminíferos começaram a se diferenciar havendo aumento do diâmetro e luz tubulares e as demais estruturas permaneceram semelhantes à observação anterior;

Dos 6 a 7 meses ocorreu o início da espermatogênese e espermiogênese; as células de Leydig apareceram maiores, poliédricas com citoplasma vacuolizado e núcleo claro e o tecido intersticial era esparso e tinha poucos vasos sangüíneos;

Os gatos com 1 ano de idade apresentaram morfologia testicular igual à do animal adulto;

Os gatos adultos apresentaram túbulos seminíferos com maior diâmetro, epitélio germinativo alto e luz tubular pequena; as células de Leydig apareceram com dimensões variadas, poliédricas, com citoplasma vacuolizado, núcleo claro e nucléolo evidente e espaço intertubular seminífero variado, com vasos sanguíneos, predominantemente evidentes;

No Gupo 1, o diâmetro médio dos túbulos seminíferos foi de $160,58 \mu \mathrm{m}$ e no grupo 2 foi de $185,94 \mu \mathrm{m}$, o que indica valores médios significantes entre si;

A altura média do epitélio seminífero foi de $49,51 \mu \mathrm{m}$ para o Grupo 1 e de $63,29 \mu \mathrm{m}$ para o Grupo 2, estaticamente significantes; e

Os maiores valores mensurados foram obtidos para os gatos do Grupo 2, por serem gatos adultos e portanto com os órgãos reprodutores funcionais.

\section{REFERÊNCIAS}

Banks W.J. 1992. Histologia Veterinária Aplicada. $2^{a}$ ed. Manole, São Paulo. 629p.

Concanon P.W. 1989. Preface and dedication. J. Reprod. Fertility 39(Suppl.):7-8.

Dellmann H.D. 1993. Histologia Veterinária. $2^{\underline{a}}$ ed. Acribia, Zaragoza. $398 p$.

Elcock L.H. \& Schoning P. 1984. Age-related changes in the cat testis and epididymis. Am. J. Vet. Res. 45:2380-2384.

França L.R. \& Godinho C.L. 2003. Testis morphometry, seminiferous spithelium cycle length, and daily sperm production in domestic cats (Felis catus). Biol. Reprod. 68:1554-1561.

Goodrowe K.L., Howard J.G., Schmidt P.M. \& Wildt D.E. 1989. Reproductive biology of the domestic cat with special reference to endocrinology, sperm function and in-vitro fertilization. J. Reprod. Fertility. 39(Suppl.):73-90.

Heyn R., Muglia U., Vizza E. \& Motta P.M. 1996. The collagen skeleton of the cat testis: A scanning electron microscopy study after $2 \mathrm{~N}-\mathrm{NaOH}$ maceration. Ital. J. Anat. Embriol. 10(3):133-140.

Hoshino P., Nakaghi L.S.O., Pacheco M.R., Lui J.F. \& Malheiros E.B. 2002. Morfometria dos túbulos seminíferos e ductos epididimários de cães e gatos provenientes de cirurgia de castração. Biotemas 15(1):97110.

Kawakami E., Tsutsui T. \& Ogasa A. 1991. Histological observations of the reproductive organs of the male dog from birth to sexual maturity. J. Vet. Med. Sci. 53(2):241-248.

Neubauer K., Jewgenow K., Blottner S., Wildt D.E. \& Pukazhenthi B.S. 2004. Quantity rather than quality in teratospermic males: A histomorphometric and flow cytometric evaluation of spermatogenesis in the domestic cat (Felis catus). Biol. Reprod. 71:1517-1524.

Nie R., Zhou Q., Jassim E., Saunders P.T.K. \& Hess R.A. 2002. Differential expression of estrogen receptors $\alpha$ and $B$ in the reproductive tracts of adult male dogs and cats. Biol. Reprod. 66:1161-1168.

Pugnetti G. 1991. Todos os Gatos. Melhoramentos, São Paulo. 136p.

Pukazhenthi B.S., Wildt D.E. \& Howard J.G. 2001. The phenomenon and significance of teratospermia in felids. J. Reprod. Fertility. 57(Suppl.):423-433.

Sánchez B., Pizarro M., Garcia P. \& Flores J.M. 1993a. Postnatal development of seminiferous tubules in the cat. J. Reprod. Fertility 47(Suppl.):343-348.

Sánchez B., Pizarro M., Garcia P. \& Flores J.M. 1993b. Histological study of Leydig cells in the cat from birth to sexual maturity. J. Reprod. Fertility 47(Suppl.):349-53

Wildt D.E., Schiewe M.C., Schmidt P.M., Goodrowe K.L., Howard J.G., Phillips L.G., O'brien S.J. \& Bush M. 1986. Developing animal model systems for embryo technologies in rare and endangered wildlife. Theriogenology 25:33-35. 